\title{
Beyond Dissection: Modifying a Traditional Crayfish Dissection Lab to teach Hypothesis Testing, Data Analysis, and Scientific Writing
}

\author{
Jessica L. Goldstein
}

Department of Biology, Barnard College, New York, New York 10027

\section{Abstract}

Traditional anatomy labs are designed to help students make connections between form and function. We found that our students focused on memorizing anatomical structures, but did not make higher-level connections about similarities and differences between particular structures. To help students think more critically, we modified our crayfish dissection lab to introduce concepts of organism variability and statistical methods to describe and compare this variability. We chose to focus on front claw size, a sexually dimorphic trait in many decapods. We also asked students to compare their findings to previous data in scientific literature and write a summary of their conclusions to teach scientific communication.

\section{Teaching Goals}

- Use statistics to describe individual variation within species

- Use data from scientific literature to form hypotheses regarding sex differences in chela size

- Collect and analyze data to test hypotheses - Communicate findings in writing

\section{Pre-Lab Information}

- Basic stats: mean, standard deviation, t-test - External anatomy: chela, cheliped, carapace - Chela function: read scientific literature

- Stein, R. A. (1976), Behaviour, 115(1), 100-113 Snedden, W. A. (1990), Canadian Journal of Zoology, 54 (2), 220-227

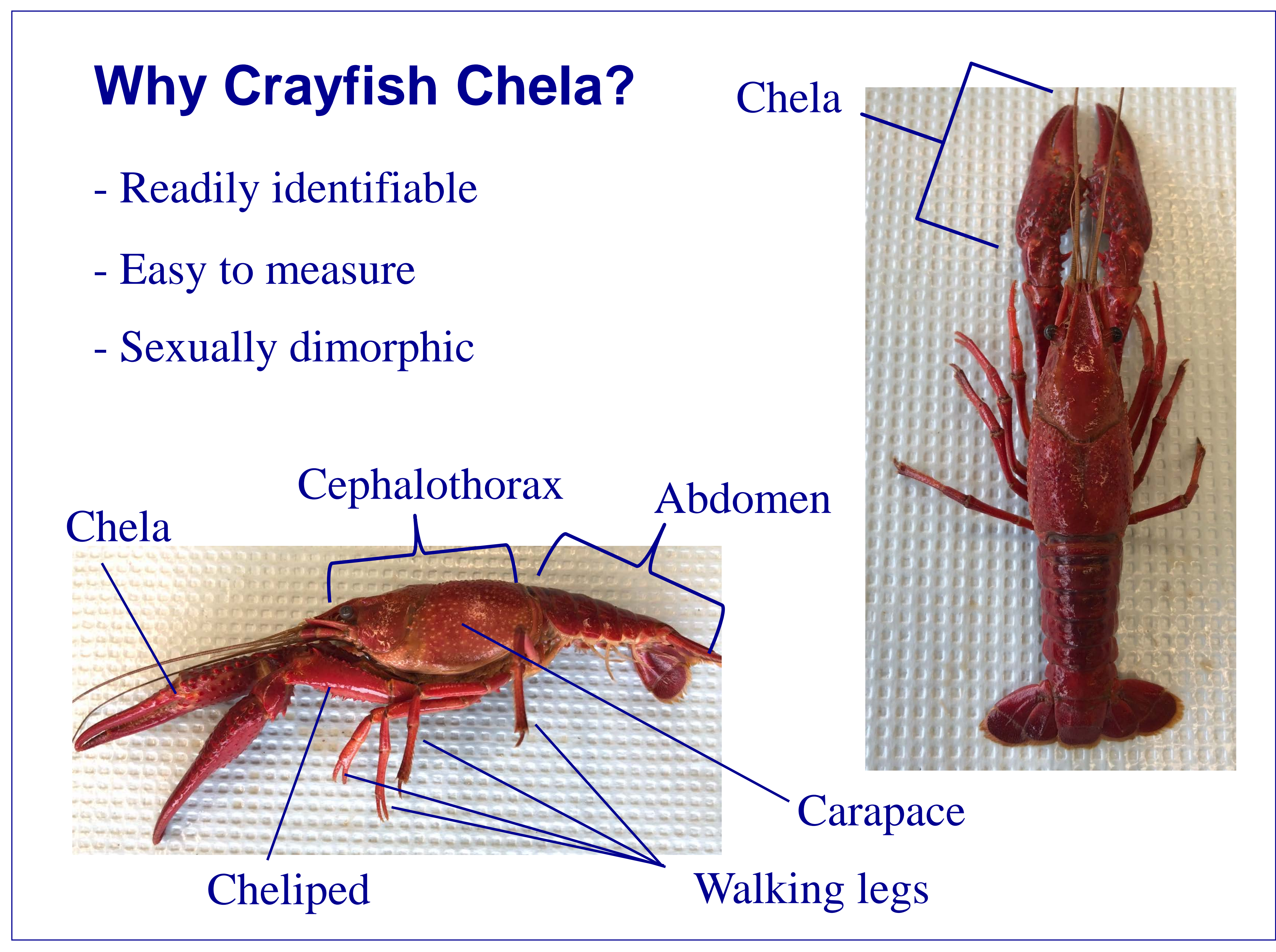

\section{Student Discussion}

Based on function, why might chela by sexually dimorphic? Refer to assigned scientific literature.

What data to collect to test hypothesis? Take into consideration that not all crayfish are the same size (e.g. normalize chela to body size).

\section{Data Collection}

Individual Data

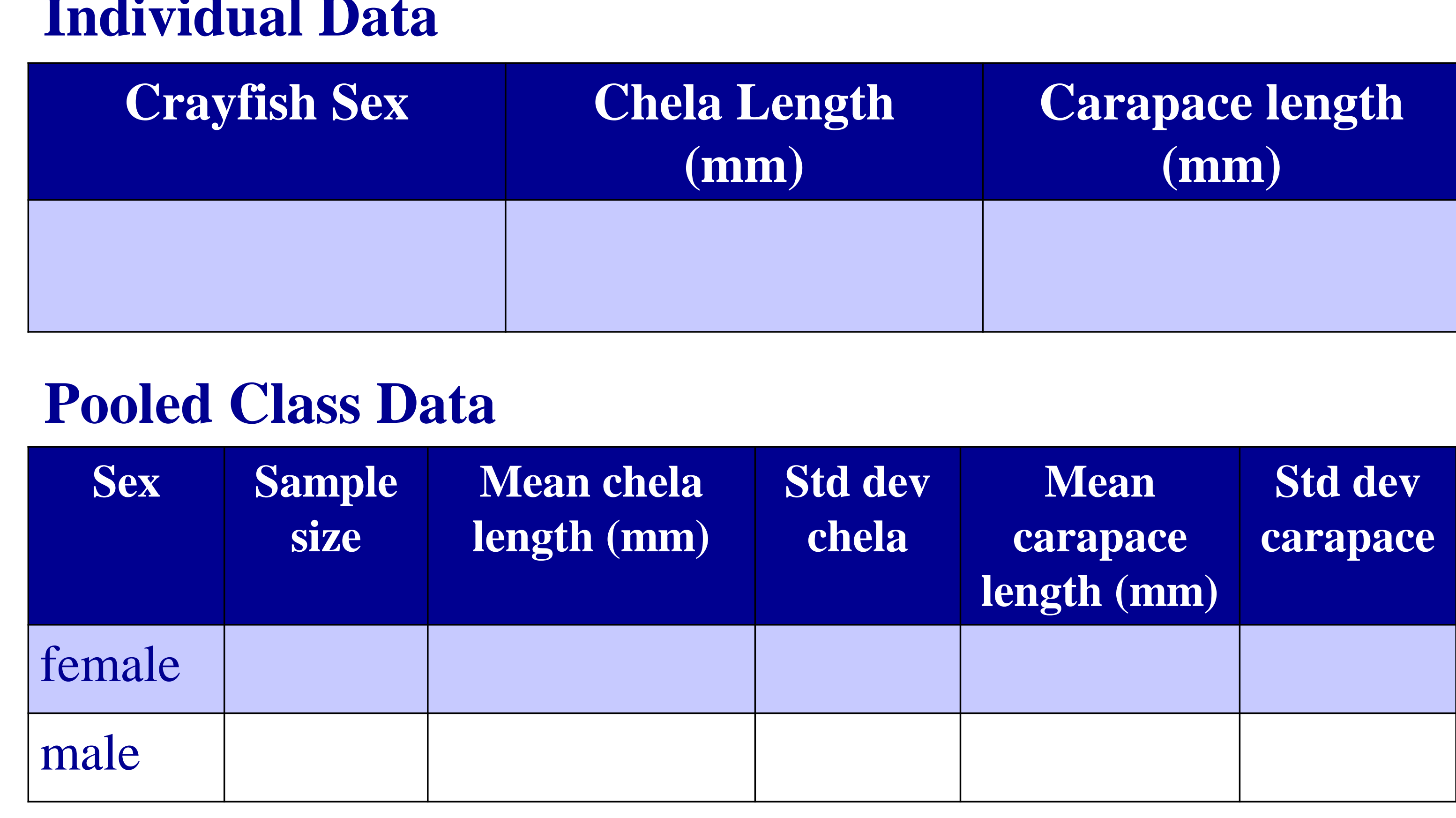

\section{Data Analysis}

Are chela sexually dimorphic in this sample?

- What values to compare?

- What statistical test to use?

\section{Homework: Results + Discussion}

Address the following questions:

- For either group ( $\mathrm{M}$ or $\mathrm{F}$ ), is there greater variability from the mean? Explain.

- Between the two sets of data (M or F), which group stats display greater reliability and why?

- Which chela is larger ( $\mathrm{M}$ or $\mathrm{F}$ ) or is there no difference?

Considering the energetic costs of producing a larger chela, propose a biological rationale for this difference (if found). Refer to assigned literature.

\section{Literature cited}

Goldstein, J. and Flynn, D. (2011) Integrating active learning and quantitative skills into introductory biology curricula. The Americ

temperate crayfish Orconectes rusticuse mating success in the competition. Behaviour, 115(1), 100-113.

Stein, R. A. (1976). Sexual dimorphism in crayfish chelae: functiond significance linked to reproductive activities. Canadian Journal of
Zoology, 54(2), 220-227.

\section{Acknowledgments}

Crayfish photographs by J. Casey. Thanks to M. Flores, J. Casey, and D. Flynn for assistance with lab development, and P. Hertz for his generous support. Funding for a portion of this project was provided by a grant to
Barnard College from the Undergaduate Science Education Program at Howard Hughes Medical Institute. 